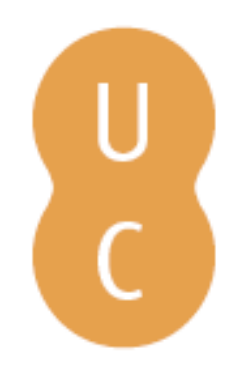

\title{
nommalina
}

\section{O contributo dos relatos e guias de viagens para o estudo da Antiguidade Clássica no Sul de Portugal}
Autor(es): $\quad$ Matos, Ana Cardoso de; Conde, Antónia Fialho; Bernardo, Maria Ana
Publicado por: Associação Portuguesa de Estudos Clássicos; Centro de Estudos Clássicos e Humanísticos; Imprensa da Universidade de Coimbra
URL persistente:
DOI:
URI:http://hdl.handle.net/10316.2/31573
DOI:http://dx.doi.org/10.14195/978-989-8281-69-2_25
Accessed : $\quad$ 26-Apr-2023 04:46:21

A navegação consulta e descarregamento dos títulos inseridos nas Bibliotecas Digitais UC Digitalis, UC Pombalina e UC Impactum, pressupõem a aceitação plena e sem reservas dos Termos e Condições de Uso destas Bibliotecas Digitais, disponíveis em https://digitalis.uc.pt/pt-pt/termos.

Conforme exposto nos referidos Termos e Condições de Uso, o descarregamento de títulos de acesso restrito requer uma licença válida de autorização devendo o utilizador aceder ao(s) documento(s) a partir de um endereço de IP da instituição detentora da supramencionada licença.

Ao utilizador é apenas permitido o descarregamento para uso pessoal, pelo que o emprego do(s) título(s) descarregado(s) para outro fim, designadamente comercial, carece de autorização do respetivo autor ou editor da obra.

Na medida em que todas as obras da UC Digitalis se encontram protegidas pelo Código do Direito de Autor e Direitos Conexos e demais legislação aplicável, toda a cópia, parcial ou total, deste documento, nos casos em que é legalmente admitida, deverá conter ou fazer-se acompanhar por este aviso.

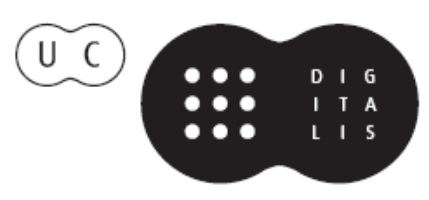




\section{Espaços e Paisagens}

Antiguidade Clássica

e Heranças Contemporâneas

Vol. III

Francisco Oliveira, Jorge Oliveira e Manuel Patrício

IMPRENSA DA UNIVERSIDADE DE COIMBRA 


\title{
O CONTRIBUTO DOS RELATOS E GUIAS DE VIAGENS PARA O ESTUDO DA ANTIGUIDADE CLÁSSICA NO SUL DE PORTUGAL
}

\author{
Ana Cardoso de Matos \\ ANTÓNIA FialHo CONDE \\ Maria Ana Bernardo \\ Universidade de Évora \\ CIDEHUS
}

\begin{abstract}
The aim of this communication is to stress the potential of reports, travel accounts and guidebooks as sources for the study of classical Antiquity. The area of analysis is Alentejo, from the seventeenth to the twentieth century.

The description of landscape elements, forms of territorial occupation and settlements, the action of men on the landscape, as well as assessments of evaluative and aesthetics parameters are an integral part of guidebooks and travel accounts. But they also have potential as repositories of information that could be used by anyone who is interested in the study of classical Antiquity. The successive images and perceptions about the classical legacy, the importance given to them in terms of speech, the reference to material and privileged vestiges and even the omissions reflect, among others, the various perspectives that authors and editors transmitted at different times and at distinct historical contexts.
\end{abstract} Keywords: heritage, memory, Reports and Guidebooks, South, travel Accounts.

Palavras-chave: memória, património, Relatos e Guias de Viagem, Sul.

\section{Introdução}

Nos últimos anos os relatos e guias de viagem têm assumido uma importância crescente como fontes históricas ${ }^{1}$. Este facto prende-se com as próprias características destas obras, nas quais se associa à descrição de determinados lugares a sua representação gráfica. Primeiro sob a forma de gravuras e mapas, depois, com a invenção e divulgação da fotografia, cada vez mais sob esta forma de fixação de imagens.

A despeito de outras eventuais funcionalidades, estes materiais pretendiam ser um "auxiliar" dos viajantes coevos. E, sendo assim, eles compreendem pelo menos dois níveis de leitura sobre o período clássico. Por um lado, num sentido mais denotativo, disponibilizam informações mais ou menos detalhadas

${ }^{1}$ F. Carmona Fernandéz; J.M. Garcia Cano 2005; J. Garcia Mercadal 1999; C. G. Romeral Pérez 2001; G. Chabaud et alii 2000. 
e rigorosas sobre sítios e vestígios arqueológicos dessa época. Podem, assim, constituir-se num pertinente meio de monitorização da evolução da produção de conhecimentos históricos e arqueológicos do período clássico. Por outro lado, os discursos veiculados em tais documentos traduzem os olhares que os respectivos autores tinham sobre as diferentes épocas e os contextos históricos a que se referiam. Os discursos veiculados permitem, também, acompanhar a produção, reprodução e apropriação de imagens sobre a importância do legado clássico num determinado país, região ou localidade.

O presente texto não é uma abordagem sistemática do tema enunciado, destinando-se tão somente a ilustrar a vantagem da inclusão dos relatos, mapas e guias de viagem para a diversificação e enriquecimento das perspectivas de estudo sobre a época clássica. Os exemplos, se bem que algo casuísticos, incidem fundamentalmente sobre o Sul de Portugal e em particular sobre Évora, região e cidade que têm sido o nosso espaço de análise preferencial quando, em função de outras problemáticas, inquirimos os relatos, a cartografia e os guias de viagens ${ }^{2}$.

\section{Mapas, itinerários e relatos de viagem no período moderno}

$\mathrm{O}$ interesse que se verificou no período moderno em relação ao mundo clássico e aos vestígios que os romanos tinham deixado na Península Ibérica foi contemporâneo de um racionalismo que se manifestou na elaboração de uma cartografia cada vez mais exacta e fiel ${ }^{3}$.

Desta forma, são diversos os mapas sobre a presença dos romanos na Ibéria e eles fornecem, nas suas legendas, para além de uma riqueza iconográfica invejável, vasta informação, de que destacamos a revelação dos Autores e documentos considerados de referência, a alusão/comparação entre os sistemas métricos coevos e os usados pelos romanos, o estatuto dos núcleos urbanos em tempos romanos, as designações latinas dos sítios, os itinerários imperiais ou a até localização de templos.

A feitura destes mapas tinha presente não apenas a literatura e a produção científica coevas como também obras que a história imortalizaria. Entre estas, eram normalmente tidas em conta as abordagens geográficas da Península por Estrabão, Pompónio Mela, Plínio e Ptolomeu, ao lado de Mapas Gerais da Espanha Antiga, impressos no século XVI, como os de Abraão Ortelio, Cristóvão Celário, Mr. D’Anville, Nicolau Sanson e Roberto Vaugondi. Em Seiscentos, os geógrafos tinham em atenção, para a feitura dos mapas, algumas obras como a Espanha Ilustrada, impressa em Frankfurt em 1603, e que, por sua vez, se inspirara em Autores portugueses: André de Resende, nas Antiguidades da Lusitânia, e Diogo Mendes de Vasconcelos, num livro

\footnotetext{
${ }^{2}$ Este texto decorre dos trabalhos que temos desenvolvido no âmbito do projecto Viagens, Turismo e Património no Sul em perspectiva histórica (séc. XVII-XX), que se encontra sedeado no CIDEHUS -UE.

3 Não esqueçamos que um dos primeiros interesses por Portugal (e das primeiras manifestações de turismo) foi o termalismo, desde o tempo dos romanos, mantendo-se ainda nos séculos XVII e XVIII. Cf. A. F. Conde 2007.
} 
sobre o município de Évora. Vemos, pois, como o mundo clássico, de forma directa ou por abordagens a esse mesmo mundo ocorridas no Renascimento, acaba por chegar aos mapas do período moderno. Temos ainda que, se em Setecentos as abordagens sobre a Lusitânia romana, em matéria cartográfica, passaram também a considerar algumas indicações da Monarquia Lusitana, de Bernardo de Brito e Frei António Brandão, e alguns tomos da Espanha Sagrada, de Fr. Henrique Florez (1756-58), esse exercício era feito depurando o discurso: sublinham-se temas como a Lusitânia e a sua metrópole (Mérida), e as áreas diocesanas (Évora, Lamego, Egitânia, Faro, por exemplo) são confrontadas com as tábuas de Ptolomeu. Também eram consultadas a obra do Padre João Baptista de Castro e a sua proposta para as vias militares romanas e para os itinerários de Antonino Pio.

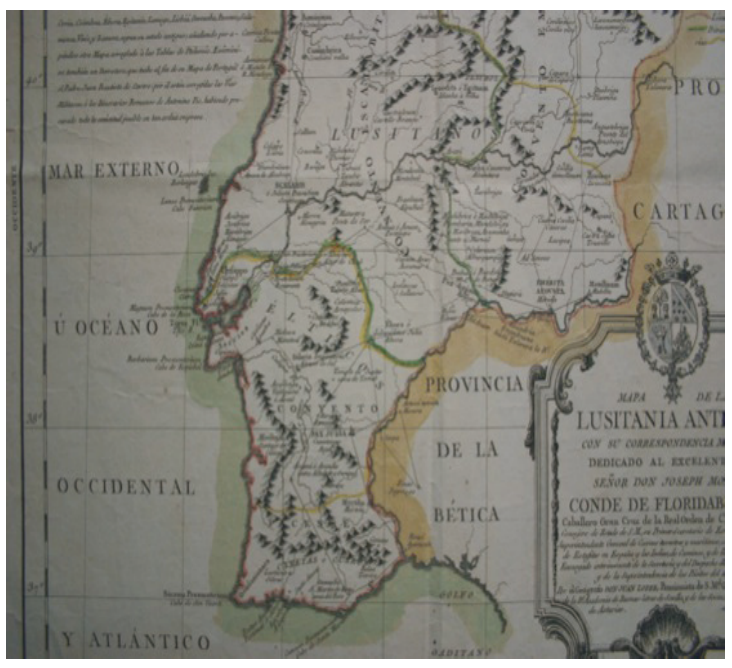

Fig.1. Mapa de la Lusitania Antigua com su correspondencia moderna, do geógrafo D. Juan Lopez, de 1789. B.P.E., Gaveta 1, Pasta A, n. ${ }^{\circ} 29$

O exemplo que escolhemos, neste contexto, é o Mapa de la Lusitania Antigua com su correspondencia moderna, do geógrafo D. Juan Lopez, de $1789^{4}$, que consideramos ser interessante para as abordagens ao tema da dominação romana na Península. Estas informações eram, à altura, bastante inovadoras, numa época em que a construção do vocabulário científico se tornava pertinente ${ }^{5}$. Este geógrafo, pensionista do rei espanhol em Paris, pertencia à Academia de Belas Artes de Sevilha e às Sociedades de Geografia da Biscaia e Astúrias. Este Mapa, que tem a preocupação de fazer corresponder os lugares da Lusitânia antiga com os topónimos coevos, foi dedicado a D. José Moñino, conde de Floridablanca. Explicita os limites das Províncias, a divisão

${ }^{4}$ B.P.E., Gaveta 1, Pasta A, n. ${ }^{\circ}$ 29. Existe exemplar semelhante na Biblioteca Nacional de Madrid (Sala Goya: Mr/2 Portugal). Cf. Figs 1 a 3.

${ }^{5}$ H. Capel 1985. 
dos conventus (para a Lusitânia, o pacense e o escalabitano) aludindo ainda aos diversos povos que aí habitaram. Na legenda, temos estatuto dos locais a que se refere: a cidade capital e convento jurídico; a colónia, o município e a cidade; a cidade mais pequena ou vila, que gozava de direito latino; os povos confederados e os estipendiários, e ainda os lugares ou aldeias. No que respeita à Lusitânia, se Beja é sinalizada como cidade capital e sede de convento jurídico, Évora, Mértola e Alcácer do Sal são indicadas como cidades menores que gozavam do direito latino, sendo Portalegre anotada como povo estipendiário e Elvas como lugar ou aldeia, ao lado de Arraiolos, Serpa, Moura.

Como acima sublinhámos, são relevadas as designações romanas das localidades, por vezes mais do que uma, bem como a sua correspondência, à altura ${ }^{6}$.

Além da precisão das coordenadas, temos também informações acerca das escalas usadas, fazendo as suas correspondências com os registos romanos e com os caminhos percorridos, em termos de tempo (um grau, em termos de longitude, correspondia a 75 milhas romanas, e cada uma correspondia, por sua vez, a 1755 varas castelhanas, por exemplo).

Este mapa permite ainda reconstituir os cinco itinerários de Antonino Augusto a partir da capital de província, Emerita Augusta; para o território português são referenciados dois itinerários, um seguindo mais pelo Norte alentejano e o curso do rio Tejo. Saía de Emerita Augusta, passava por Plagiaria, Pax Augusta e ia até Septem Aras, onde bifurcava; uma das vias seguia por Malusaro, Alberteri, Bretolacum e chegava a Ollisypo. A outra seguia no sentido da Aramenha, povo estipendiário, Fraavium, Tucubis, Scalabis, Arabriga, outro povo estipendiário, chegando a Olissipo.

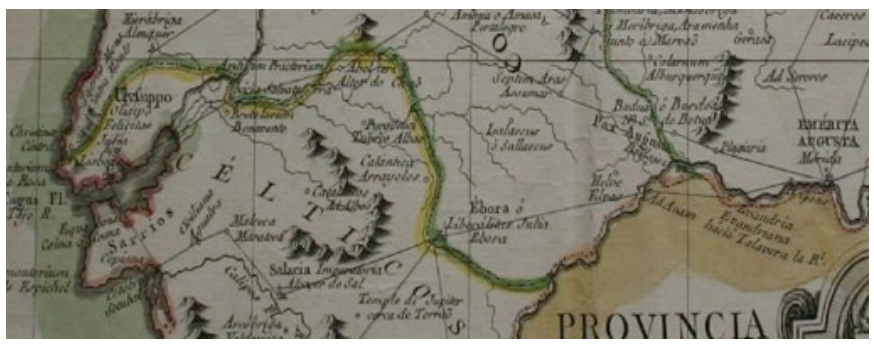

Fig.2. Itinerários a partir de Emerita Augusta. B.P.E., Gaveta 1, Pasta A, n. ${ }^{\circ} 29$

O outro itinerário vinha mais para o sul, dividindo-se, em Liberalitas Julia em duas vias, uma mais longa, que percorria o interior, e outra que seguia no sentido do litoral. Assim, de Emerita Augusta este itinerário seguia por Evandria até Liberalitas Julia, onde se dividia: uma das vias seguia para Salacia Imperatoria, Malceca, Ciciliana, Cetobriga, Equabona e atingia Olissypo. A outra seguia no sentido de Rarapia, Aranni (entre Alvalade e Ourique, povo

\footnotetext{
${ }^{6}$ Casos de Balsa, Tavira; Myrtilis, Mértola; Pax Augusta, Badajoz; Malusaro, Ponte de Sôr; Fraavium, Alpalhão; Mendicular, Montalvão; Moren, Almeirim.
} 
estipendiário), Ossonoba/Estoi, Balsa, Esuri (Ayamonte), Myrtillis, Pax Julia, Arucci Novum, Fines (povo estipendiário), Serpa, e chegava de novo a Liberalitas Julia. O testemunho do mapa pode ser confrontado com fontes documentais existentes em Évora? ${ }^{7}$.

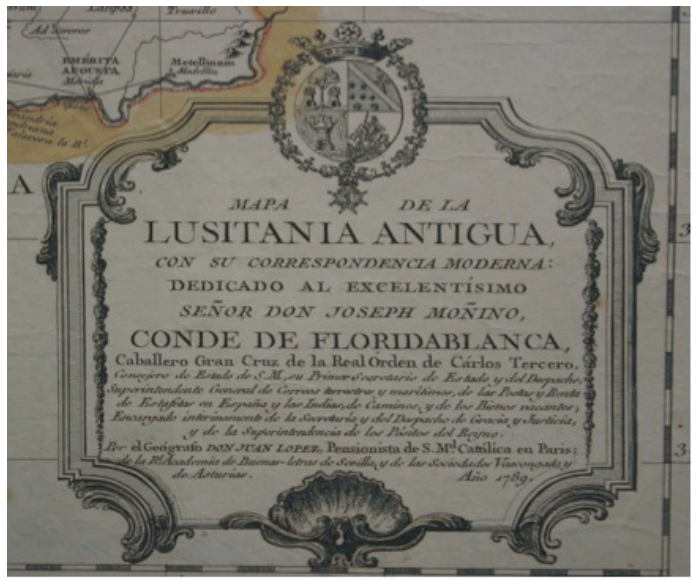

Fig.3. Mapa da Lusitânia Antiga: autoria, dedicatória e data. B.P.E. Gaveta 1, Pasta A, nº29

Nos Relatos de Viagens, para este período e dentro desta temática, salientamos o discurso de D. Juan Alvarez de Colmenar, no terceiro tomo da obra Annales d'Espagne et de Portugal, da década de 40 do século XVIII. Na obra é feita uma descrição geral do reino e das cidades a partir das províncias onde se localizavam. Embora os aspectos bélicos estejam muito presentes, o autor preocupa-se com a descrição latina dos sítios, descrevendo ainda vestígios antigos, como o templo de Prosérpina, em Vila Viçosa, ou fazendo a transcrição lapidar do que encontrou no convento dos Agostinhos da mesma vila. Em relação a Évora, elogia a sua ancestralidade, em particular a sua romanidade: Júlio César dera-lhe o direito de cidade latina, com o nome de Liberalitas Julia, designação que, segundo o viajante, terá encontrado numa inscrição aquando da sua visita à cidade; Sertório guarnecera-a de boa cintura de muralhas, bem como de um magnífico aqueduto, mais tarde elogiado também por James Murphy.

Murphy foi outro viajante que, no século XVIII, visitou o Sul de Portugal, tendo como objectivo primordial estudar e desenhar os monumentos portugueses e as preciosidades arqueológicas a pedido de William Burton Conyngham, seu protector, e que antes visitara o país. Mercê da sua formação em arquitectura e arqueologia, o seu relato revela um grande interesse pelos vestígios antigos, particularmente os romanos. Deste modo, sublinha as

${ }^{7}$ B.P.E., Cód. 76 da Manizola, Peça 33. Neste códice são transcritas diversas inscrições encontradas ao longo do Itinerário, muitas vezes socorrendo-se do trabalho já efectuado por André de Resende. 
qualidades de Salacia Imperatoria (Alcácer do Sal) como estância balnear desde a época romana e os vestígios romanos próximos, como os de um templo dedicado à deusa Salacia. Já em Beja, além dos elogios às recentes escavações, o Autor admira a colecção de objectos recolhidos por Frei Manuel do Cenáculo. Desenha-os, deixando-nos na sua obra, também enquanto artista, um importante testemunho para o estudo da época. Teve comportamento similar em Évora, onde se detém nos seus símbolos maiores de ligação à presença romana: o templo e o aqueduto, que desenha, descreve e elogia. Descreve também em pormenor a torre/reservatório existente na extremidade do aqueduto, com a designação de $\mathrm{S}$. Francisco, elogiando os materiais e a sua harmonia, lembrando-lhe as obras gregas. Refere-se a essa torre como o mais bem conservado e mais belo monumento da Antiguidade de Évora.

\section{Os guias de viagens nos períodos moderno e contemporâneo}

Os guias de viagem têm uma tradição que remonta a períodos recuados e os primeiros que se conhecem eram destinados aos peregrinos que se dirigiam Roma, S. Tiago de Compostela ou Jerusalém e estavam escritos em latim. Nestes guias eram dadas indicações como as etapas da viagem, as grandes hospedarias, as cidades e vilas por onde se devia passar. No período moderno foram impressos vários guias, como foi o caso do Guide de chemins de France da autoria de Charles Estienne, datado de 1552, ou do guia Le Guide des chemins d'Angleterre, da autoria de Jean Bernard, que foi publicado em $1579^{8}$. Contudo foi a partir do século XVIII que se desenvolveu a publicação de guias de viagens em que se davam indicações concretas e úteis sobre os espaços a visitar, como é o caso do Guide du Voyageur par Angleterre et Hollande (Paris, 1786). Surgiram mesmo colecções de bolso em que se indicavam os monumentos mais representativos ou pitorescos de cada localidade, como foi o caso da colecção francesa Delices de..., na qual em 1707 se publicou a obra Delices de l'Espagne et du Portugal ${ }^{9}$.

Os guias de viagens do período contemporâneo inserem-se numa literatura utilitária e pedagógica que visa dar àqueles a quem se dirigem uma série de indicações práticas sobre as viagens a empreender e sobre os espaços a $\operatorname{visitar}^{10}$. Disponibilizavam igualmente informações de carácter histórico, mais ou menos pormenorizadas e rigorosas, sobre os vários lugares ou monumentos referidos nos itinerários que eram propostos ${ }^{11}$.

Entre as estratégias concebidas para incentivar a visita a determinados espaços e locais, contam-se as referências à sua antiguidade, fazendo-a remontar, em alguns casos, ao período clássico. Nos guias de viagem, a antiguidade clássica está presente através de aspectos como: referências e descrição de determinados espaços, tais como os museus de arqueologia;

${ }^{8}$ G. Guilcher 200082.

${ }^{9}$ P. van der Aa 1707. Nas versões francesas surge como autor Juan Álvarez de Colmenar, talvez um pseudónimo do verdadeiro autor.

${ }^{10}$ Sobre os Guias de Turismo veja-se A. C. de Matos e M. L. Santos 2004.

${ }^{11}$ M. L. Santos, A. C. de Matos, M. A. Bernardo 2008. 
chamadas de atenção para a relevância que determinadas povoações ou lugares tinham no período clássico; localização e descrição mais ou menos detalhada de sítios com vestígios daquele período; reconstituições de viagens e da rede viária; imagens da cidade, etc.

Por efeito de um processo de especialização temática em função dos públicos a que se dirigiam, já no século XX, no final dos anos 1970 início de 1980, os arqueólogos e historiadores Filippo Coarelli e Mario Torelli criaram a colecção Guide Archaelogiche Laterza, que era composta por 14 volumes e abrangia a Itália, a Sicília e a Sardenha. Esta colecção tinha por objectivo dar a conhecer as descobertas arqueológicas e as campanhas arqueológicas recentes ${ }^{12}$.

O interesse que durante o século XIX se verifica em Portugal relativamente à antiguidade clássica enquadra-se no facto de se iniciarem "neste século, campanhas de pesquisas, sobretudo nos locais arqueológicos há muito conhecidos: Tróia, Lisboa, Conímbriga e Évora, sítios onde as investigações se assumem já com um carácter tendencialmente institucionalizado"13. Campanhas que eram largamente divulgadas não só em publicações especializadas que se destinavam aos arqueólogos, mas também noutras que eram dedicadas a um público mais heterogéneo, como no caso de $O$ Archivo Popular, que em 1838 noticia o aparecimento de uma inscrição numa parede de uma casa, na Travessa do Almada em Lisboa, ou do Archivo Pittoresco, que em 1863 refere o achado de uma urna de vidro, presumivelmente romana, com inscrição funerária, numa escavação em Setúbal ${ }^{14}$.

Os exemplos que se seguem, relativos ao Sul do país, e em especial a Évora, ilustram o testemunho da presença da antiguidade clássica nos guias de viagem dos séculos XIX e XX editados em português.

Comecemos pelo Novo Guia Luso-Brasileiro do viajante na Europa ${ }^{15}$, datado de 1876 e da autoria de Guilherme João Carlos Henriques, que se destinava aos viajantes portugueses e brasileiros que pretendiam conhecer a Europa. Nesta obra são várias as referências aos monumentos da antiguidade que o autor aconselha o viajante/turista a visitar, como é o caso do "Templo de Diana, uma antigualha romana muito visitada pelos archeologos estranjeiros; o aqueducto do Sertorio, que data da mesma era; a Torre da extremidade do aqueducto, um primor de architectura romana" ${ }^{16}$, ou o caso de "S. Thiago de Cacem. Cabeça de Comarca e aceiada povoação. É muito frequentada pelos

${ }^{12}$ G. Guilcher 2000181 e 184 . Todos os autores dos guias eram arqueólogos.

${ }^{13}$ O. Matos 2007 75-96.

${ }^{14}$ Idem.

15 Tratava-se de um livro de pequenas dimensões, com 541 páginas, o qual, após uma introdução, se dividida em capítulos que correspondiam aos diferentes países, terminando com um índice geral alfabético. A principal razão que levou o autor a escrever foi o facto de "Por muitos annos houve falta d'um livro em portuguez que indicasse aos viajantes portuguezes e brazileiros os itenerarios mais seguidos e os meios de communicação mais asselerados entre as diversas capitaes da Europa".

${ }^{16}$ G. J. C. Henriques 1876 38-39. 
estrangeiros que vão ver as ruinas da antiga Merobriga, cidade romana, que fica a 1 kilometro de S. Thiago"17.

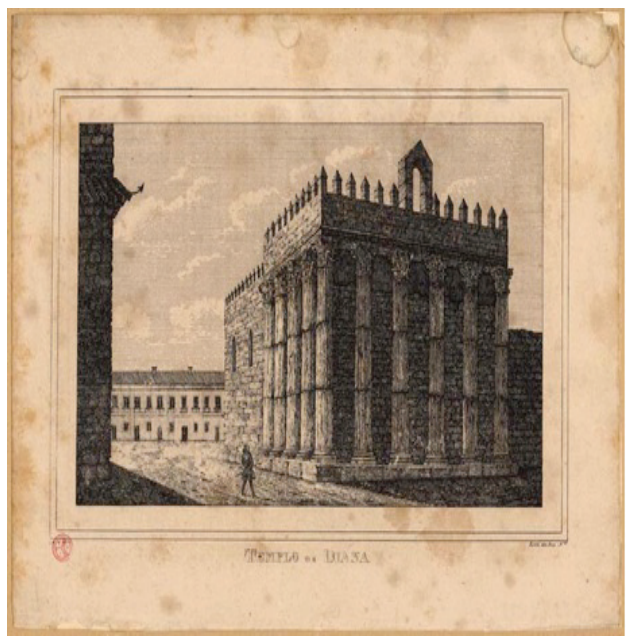

Fig.4. Templo de Diana em Évora, in James Murphy, Voyage en Portugal a Travers les

Provinces D'Entre Douro et Minho, de Beira, D'Estremadure et D'Alenteju dans les Annés 1789 et 1790. Paris, Chez Denné Jeune, 1797.

O interesse de Guilherme João Carlos Henriques ${ }^{18}$ pela antiguidade clássica estava também seguramente ligado ao facto de ele ser um erudito que pertenceu à Real Associação dos Arquitectos e Arqueólogos Portugueses, onde naturalmente existia um grande interesse pelas referências à antiguidade clássica.

No início do século XX o engenheiro Caetano da Câmara Manuel, que durante largos anos dirigiu as obras públicas na cidade de Évora, tendo-se mesmo tornado um eborense de adopção ${ }^{19}$, escreveu a obra Atravez da Cidade de Évora. Apontamentos sobre a cidade de Évora e os seus arredores ${ }^{20}$, na qual pretendia "Dar uma sumária notícia de Évora monumental, não deixando, contudo, de acompanha-la de alguns apontamentos que possam interessar ao forasteiro", que se destinava aos "interessados da história de Évora" e aos visitantes desta cidade. Não sendo um historiador, baseava-se na Historia de exercito portuguez por Christovão Ayres, para referir que "A cidade romana era cercada de uma muralha que teria $1080 \mathrm{~m}$ de extensão e seguia pela Alcarcova de baixo e de cima, Igreja do Salvador, arco de D. Izabel, muralha

${ }^{17}$ Idem, 39-40.

18 Terá nascido em Londres em 27 de Março de 1846 com o nome de William John Charles Henry, que depois alterou. Era afilhado do Conde de Carnota e foi proprietário rural e autor de obras como Alenquer e o seu concelho. Lisboa, Typographia Universal, 1873.

${ }^{19}$ J. Pereira 2007.

${ }^{20}$ C. C. Manoel 1900. Trata-se de um livro de pequenas dimensões, com 104 páginas e algumas fotografias. 
norte do passeio de Diana, palacio dos Condes de Basto (hoje do conde da Serra da Tourega), onde existiu uma mouchinha, Freiria de baixo ao largo da Misericórdia, e Igreja de S. Vicente"21.

As referências ao período clássico surgiram também num guia editado pela primeira vez em 1907 pela revista Gazeta dos Caminhos de Ferro e coordenado por L. de Mendonça e $\operatorname{Costa}^{22}$, um dos portugueses que no início do século XX mais viajou e mais promoveu o turismo em Portugal. Tal guia tinha por título $\mathrm{O}$ Manual do Viajante em Portugal: com itinerários da viagem em todo o paiz e para Madrid, Paris, Vigo, Sant'Iago, Salamanca, Badajoz e Sevilha ${ }^{23}$.

Sobre a questão da atribuição aos romanos de algum património edificado existente na cidade de Évora pode ler-se, no referido guia: a «Torre do Sertório, que muitos supõem romana. É de construção medieval [...]» ${ }^{24}$.

As referências à antiguidade das várias cidades e vilas do país surgem também no Guia de Portugal de Raul Proença. Aí se refere que "O Templo romano (mon. Nac. Pl. C6 n ${ }^{\circ}$ ), vulgarmente denominado templo de Diana (embora ainda hoje se desconheça a que divindade era dedicado) é único no seu género e uma das mais bem conservadas ruínas romanas de toda a Península. É uma combinação de robustez e graça [...] (Para mais pormenorizada descrição cf. G. Pereira, Estudos Eborenses - Évora romana, $1^{\mathrm{a}}$ parte [...])”.

\section{Considerações finais}

Os exemplos que acima enunciámos permitiram demonstrar o contributo que os mapas, os relatos e os guias de viagem podem fornecer para o estudo da Antiguidade Clássica. Em especial os estudos que têm como objectivo conferir o que em cada momento histórico se sabia sobre os vestígios que os povos antigos deixaram no nosso território e a forma como esse legado foi sendo percepcionado e valorizado ao longo dos tempos.

\section{Bibliografia}

P. van der Aa, ed. (1707), Les delices de l'Espagne et du Portugal. Leide, 3 vols. Biblioteca Nacional de Madrid, (B.N.M.), Sala Goya, Mr/2 Portugal.

Biblioteca Pública de Évora (B.P.E.), Gaveta 1, Pasta A, nº 29 (Cartas Geográficas).

${ }^{21}$ Idem, p.21.

22 Sobre Mendonça e Costa, promotor da referida Gazeta dos Caminhos de Ferro de Portugal e Hespanha, veja-se E. Ribeiro 2006.

${ }^{23}$ Este livro com formato "de bolso" e capa de cor azul imperial e letras brancas (cores da bandeira nacional), possuía 252 páginas de leitura. Mendonça e Costa utilizou como modelo, segundo as próprias palavras, os guias de Baedeker; era seu objectivo proporcionar, em língua portuguesa, um guia de viagem em Portugal, já que os guias existentes eram escritos noutras línguas.

${ }^{24}$ R. Proença 1924-27: Vol. II, p. 62. 
Biblioteca Pública de Évora (B.P.E.), Cód. 76 da Manizola, Peça 33: Itinerário de Antonino pello Reyno de Portugal, e Província de Estremadura, com alguas illustracões. Caminho de Lisboa a Merida, M.P.CXLI.

D. Juan Alvarez de Colmenar (1741), Annales d'Espagne et de Portugal avec la description de ces deux royaumes. Amsterdam, François L'Honoré \& Fils, Vol. III.

L. de Mendonça Costa e Carlos d'Ornells (1940), O Manual do Viajante em Portugal: com itinerários da viagem em todo o paiz e para Madrid, Paris, Vigo, Sant'Iago, Salamanca, Badajoz e Sevilha. Lisboa, Gazeta dos Caminhos de Ferro.

Guilherme João Carlos Henriques (1876), Novo Guia Luso-Brasileiro do viajante na Europa. Lisboa, Editores Ferreira-Lisboa \& $\mathrm{C}^{\mathrm{a}}$.

Caetano da Câmara Manoel (1900), Atravez da Cidade de Évora ou apontamentos sobre a cidade e os seus monumentos. Évora, Minerva Comercial.

James Murphy (1797), Voyage en Portugal a Travers les Provinces d'Entre Douro et Minho, de Beira, d'Estremadure et d'Alenteju dans les annés 1789 et 1790. Paris, Chez Denné Jeune.

Raul Proença (1924-1927), Guia de Portugal. Lisboa, Oficinas Gráficas da Biblioteca Nacional.

Estudos

Horácio Capel (1985), "Geografia y Arte Apodémica en el siglo de los viajes", Geocritica. Cadernos Críticos de Geografia Humana. Universidad de Barcelona, Año 9, $\mathrm{N}^{\circ}$ 56. (disponível em http://www.ub.es/geocrit/geo56 htm). Antónia Fialho Conde (2007), "On Continuity of Choice: the Places and Spaces Visited by Tourists and Travellers in Portugal in the 18th and 19th centuries", Things that move: The material world of tourism and travel. Leeds, Centre for Tourism \& Cultural Change.

Fernando Carmona Fernandéz, José Miguel Garcia Cano, eds., (2005), Libros de viaje y viajeros en la literatura y en la historia. Universidad de Murcia.

Goulven Guilcher (2000), «Naissance et développement du guide de voyage imprimé: du guide unique à la série, une stratégie de conquête des lecteurs ?», in Gilles Chabaud et alii, Les Guides Imprimés du XVIe au XXe Siècle : villes, paysages, voyages. Paris, Belin, 81-93.

Ana Cardoso de Matos, Maria Luísa F. N. dos Santos (2004), "Os guias de Turismo e a emergência do Turismo Contemporâneo em Portugal (dos finais do século XIX às primeiras décadas do século XX)", Scripta Nova. Revista electrónica de Geografía y Ciencias Sociales. Universidad de Barcelona, Vol. VIII, núm. 167. (disponível em http://www.ub.es/geocrit/sn/sn-167.htm).

Olga Matos (2007), "Notas soltas sobre a 'descoberta' da Arqueologia no século XIX" Praxis Archaeologica. Revista Electronica de Teoria, Metodologia e Política da Arqueologia 2 75-96.

José Garcia Mercadal (1999), Viajes de extranjeros por España y Portugal: desde los tiempos remotos hasta comienzos del siglo XX. Salamanca, Junta de Castilla y León, 6 vols. 
João Pereira (2006), A intervenção dos Engenheiros e Condutores na modernização da cidade de Évora (1880-1920). Évora (dissertação de mestrado).

Carlos Garcia Romeral Pérez, (2001), Bio-bibliografía de viajeros por España y Portugal. Madrid, ed. Ollero e Rams, 3 vols.

Elói Ribeiro (2006), A Gazeta dos Caminhos de Ferro e a Promoção do Turismo em Portugal (1888-1940). Évora (dissertação de mestrado).

Maria Luísa Santos, Ana Cardoso de Matos, Maria Ana Bernardo (2008), "Tourism, Guidebooks and the Emergence of Contemporary Tourism in Portugal", Touring the Past. Finnish University Network for Tourism Studies (forthcoming). 